Ariane Dierke*, Thomas Kuske, Hagen Frank, Eric Bohne, Christoph Brandt-Wunderlich, Luise Knorre, Michael Stiehm, Andrea Bock, Niels Grabow, Andreas Wree, Marek Zygmunt, Klaus-Peter Schmitz, Stefan Siewert

\title{
Validation of Finite Element Analysis of a self- expanding polymeric microstent for treatment of Fallopian tube occlusions
}

\begin{abstract}
Proximal occlusion of the Fallopian tube is one of the most common causes of female infertility. Due to the occlusion, the passage of the fallopian tubes is no longer given. Basically, there are two options for patients affected by this condition: cost-intensive in vitro fertilization (IVF) or surgery. The pregnancy rates of approximately $50 \%$ achieved with current treatment options are not satisfying. In this work, we present a Finite Element Analysis (FEA) model of a previously reported optimized microstent design for minimally invasive therapy of proximal tubal occlusion. Based on experimental investigations, the material model was set up and the simulation was validated. Comparison of the mechanical performance as an application related critical load case was in a good agreement. In this work, the proof of concept for the FEA model and the material model were carried out. In the future, the simulation will be used for further load cases such as the investigation of the bending stiffness and radial force and for the design optimization.
\end{abstract}

Keywords: biodegradable microstent, Fallopian tube occlusion, enabling pregnancy, fertility treatment, FEA.

https://doi.org/10.1515/cdbme-2021-2178

\footnotetext{
*Corresponding author: Ariane Dierke: Institute for ImplantTechnology and Biomaterials e.V., Friedrich-BarnewitzStr. 4, 18119 Rostock-Warnemünde, Germany, e-mail: ariane.dierke@uni-rostock.de Thomas Kuske, Hagen Frank, Eric Bohne, Christoph BrandtWunderlich, Michael Stiehm, Andrea Bock, Klaus-Peter Schmitz, Stefan Siewert: Institute for ImplantTechnology and Biomaterials e.V., 18119 Rostock-Warnemünde, Germany Luise Knorre, Niels Grabow, Klaus-Peter Schmitz: Institute for Biomedical Engineering, Rostock University Medical Center, 18119 Rostock-Warnemünde, Germany

Marek Zygmunt: Department of Obstetrics and

Gynecology,University Medicine Greifswald, 17475 Greifswald, Germany

Andreas Wree: Department of Anatomy, Rostock University Medical Center, 18057 Rostock, Germany
}

\section{Introduction}

Female sterility is caused by proximal tube occlusions in one out of three cases [1]. The occlusion limits the functionality of the fallopian tube as a hormonal valve. Moreover, the Fallopian tube is no longer passable for ovum and sperm. This results in either an increased probability of tubal pregnancy or sterility.

Currently, patients with an unfulfilled wish to have children have to choose between in vitro fertilization (IVF) or surgery. The former is associated with high costs, which are only covered up to $50 \%$ by health insurance in germany [2] In addition, the procedure is performed in cycles, with a pregnancy rate of $80 \%$ achieved only after the fifth. Surgical overcoming of the constriction is an irreversible intervention, through a pregnancy rate of up to $50 \%$ can be achieved [3].

These methods cause a high level of psychological stress and the pregnancy rates achieved are not satisfying. A minimally invasive, reversible form of treatment is needed. Our previously described polymeric microstent represents a promising therapy option [4]. Figure 1 illustrates the functional concept.

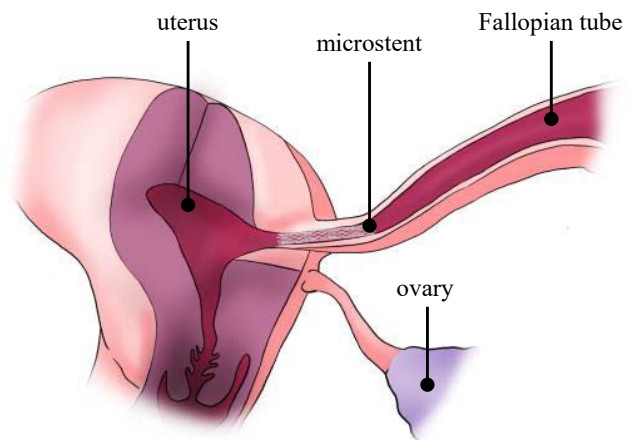

Figure 1: Illustration of microstent inside the Fallopian tube.

As part of the development of a self-expandable, biodegradable polymer stent, design optimization must be performed with regard to the requirements of the implantation site. For this purpose, a finite element model is created in order to adapt the design with regard to occurring tensions and strains. 


\section{Materials and methods}

\subsection{Microstent design}

The microstent design was developed using 3D-CAD (computer-aided design) software Creo Parametric 6.0 (PTC Inc., USA), see Figure 2.

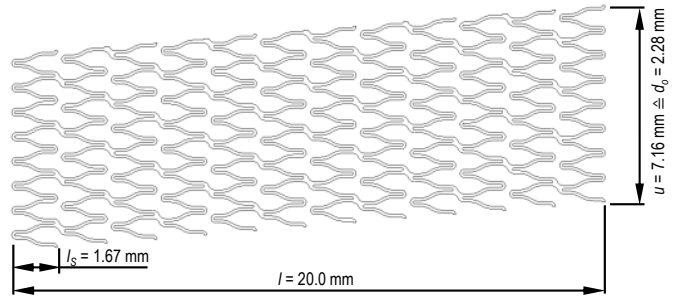

Figure 2: Two-dimensional representation of the microstent design with an outer diameter of $2.28 \mathrm{~mm}$.

To ensure the functionality of the cilia of the Fallopian tube, a small surface coverage is targeted with the stent design. Regarding the anatomical boundary conditions, especially the need of a high flexibility, the stent design was considered as an open-cell design with different diameter variations and lengths. The current work depicts the FEA with the largest outer diameter of $2.28 \mathrm{~mm}$, a stent length of $20 \mathrm{~mm}$, a wall thickness and strut width of $100 \mu \mathrm{m}$.

\subsection{Manufacturing of microstent- prototypes}

For preparing tubular semifinished products, $12 \mathrm{~g}$ Poly(Llactide) (PLLA, Resomer L210, Evonik Health Care GmbH, Germany) in $400 \mathrm{ml}$ chloroform (Carl Roth $\mathrm{GmbH}+$ Co. $\mathrm{KG}$, Germany) was utilized in a solution for the dipping process. PLLA as an absorbable thermoplastic polymer has been successfully used in medical devices. According to the literature, there are adequate mechanical properties, such as a high elastic modulus $1,200 \mathrm{MPa} \leq E \leq 2,700 \mathrm{MPa}$, a tensile strength of $28 \mathrm{MPa} \leq \sigma_{m} \leq 50 \mathrm{MPa}$ and an elongation at break of $\varepsilon_{B}=6 \%$. The absorption rate ranges between 1.5 to 5 years [5].

Achieving the wall thickness of $100 \mu \mathrm{m}$ is verified by measurement of tubing outside diameter by means of a biaxial laser system (ODAC $32 \mathrm{XY}$, ZUMBACH Electronic AG, Switzerland). Manufacturing of microstent prototypes was conducted using the StarCut Tube fs-laser system (Coherent, Inc., Santa Clara, California, USA). Therefore, a numerical control file was created using CAGILA (CAMService GmbH, Hannover, Germany).

\subsection{Experimental investigations and Finite Element Analysis of microstent}

Finite Element Analysis (FEA) was conducted using the software ANSYS Workbench (ANSYS Inc., Canonsburg, Pennsylvania). The calculation within the FEA is implemented with a half model. This is possible due to the symmetrical stiffness. The meshing is done with linear hexahedral elements, whereby potentially highly stressed regions in the tight radii are meshed much finer $(0.025 \mathrm{~mm})$ than the struts $(0.1 \mathrm{~mm})$. Three elements are placed along the wall thickness. Self-contact is defined between the struts.

The material model is based on the investigation of polymer (PLLA) tubular semifinished products using the 3-point bending test according to DIN EN ISO 178:2019-08. During the test, Young's Modulus $(E)$, Yield Strength $\left(\sigma_{y}\right)$ and Tangent Modulus $\left(E_{T}\right)$ were investigated to create a bilinear constitutive law for PLLA considering isotropic hardening. Figure 3 shows the corresponding stress-strain diagram.

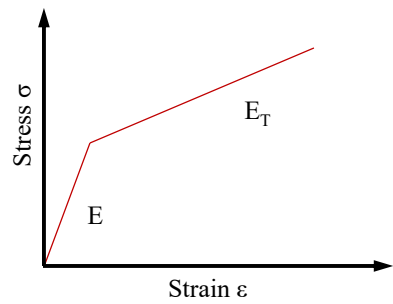

Figure 3: Bilinear uniaxial stress-strain curve for plasticity.

The test is conducted at $37^{\circ} \mathrm{C}$. Figure 4 illustrates the experimental setup which was also implemented in FEA.

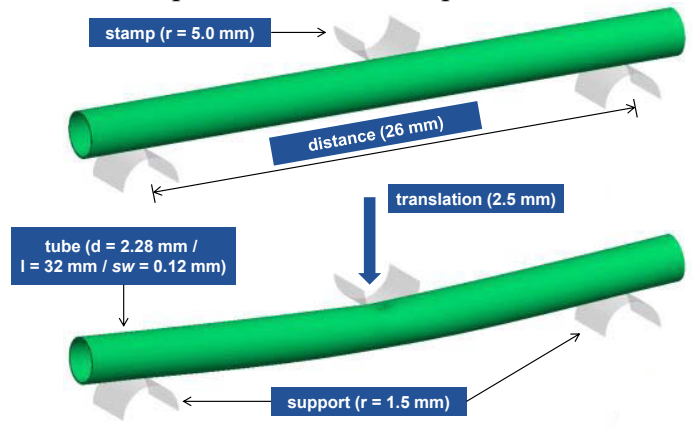

Figure 4: Schematic setup of 3-point bending test.

The obtained mechanical parameters are verified within a FEA model of the 3-point bending test. For this purpose, a load case is designed with one movable stamp and two mountings.

For validation of the FEA model, the load case crush resistance according to DIN EN ISO 25539-2:2021-01 was chosen. 
The test is conducted at $37^{\circ} \mathrm{C}$. Following the test standard DIN EN ISO 25539-2:2021-01, the mechanical characterization is carried out on a universal testing machine (zwickiLine, Zwick/Roell AG, Germany). The force is recorded using a $20 \mathrm{~N}$ load cell (Xforce HP, Zwick/Roell, Germany). The measuring interval covers an ovalization from $2.2 \mathrm{~mm}$ to $1.1 \mathrm{~mm}$ in $0.1 \mathrm{~mm}$ increments. A testing speed of $0.005 \mathrm{~mm} \mathrm{~min}^{-1}$ and a static preload of $4 \mathrm{mN}$ was used.

For FEA, the load case crush resistance consists of the stent and two rigid plates. The upper plate is defined as movable while the lower plate is fixed. The initial plate distance is defined as $2.5 \mathrm{~mm}$. The upper plate moves towards the lower plate up to a minimum distance of $1.1 \mathrm{~mm}$, see Figure 5.

a)

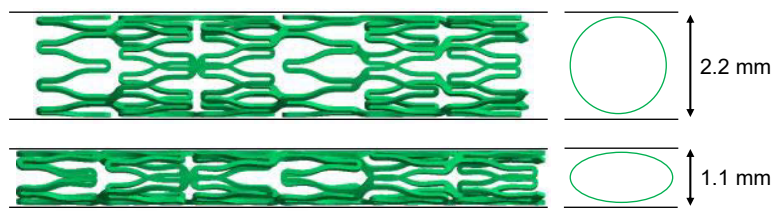

Figure 5: Illustration of the load case step for crush resistance. a) initial diameter of $2.2 \mathrm{~mm}, \mathrm{~b}$ ) ovalization to $1.1 \mathrm{~mm}$.

This distance corresponds to the tool distance during the experimental studies. Then the simulation of the release due to the backward movement of the upper plate is carried out. The forces and the opening diameter after ovalization are measured.

\section{Results}

\subsection{Manufacturing of microstent- prototypes}

For microstructuring ten tubular semifinished specimens with reproducible outer diameter of $(2.280 \pm 0.004) \mathrm{mm}$ were provided. Further processing resulted in eight microstent prototypes with a strut width $(s w)$ and wall thickness (st) of approximately $s w=(105.5 \pm 0.5) \mu \mathrm{m}$ and $s t=(94.4 \pm 5.1) \mu \mathrm{m}$. Figure 6 shows a macro image of a microstent prototype.

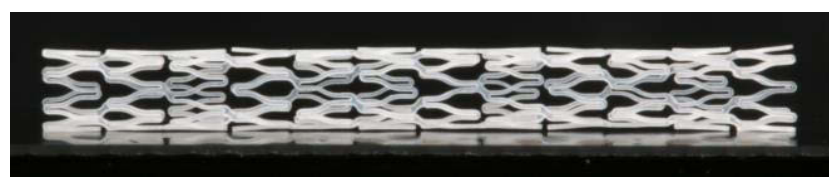

Figure 6: Macro image of a microstent prototype.

\subsection{Experimental investigations and Finite Element Analysis of microstent}

Force-displacement curves resulting from experimental characterization of tubular specimens by means of the 3-point bending test are shown in Figure 7.

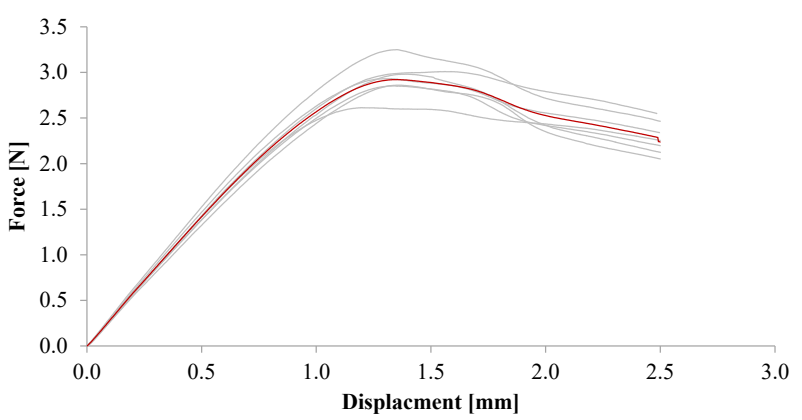

Figure 7: Force-displacement curves resulting from experimental characterization of tubular specimens by means of the 3-point bending test: individual specimens (grey, $n=7$ ) compared with the mean value curve (red).

The mean value curve was used to adapt the constitutive law. Material parameters resulting from the iterative adaption process are summarized in Table 1.

Table 1: Final material parameters for a bilinear constitutive law for PLLA considering isotropic hardening.

\begin{tabular}{llll}
\hline $\begin{array}{l}\text { Young's } \\
\text { Modulus } E\end{array}$ & $\begin{array}{l}\text { Poisson's } \\
\text { ratio } \boldsymbol{v}\end{array}$ & $\begin{array}{l}\text { Yield } \\
\text { Strength } \boldsymbol{\sigma}_{\boldsymbol{y}}\end{array}$ & $\begin{array}{l}\text { Tangent } \\
\text { Modulus } E_{T}\end{array}$ \\
\hline $3,000 \mathrm{MPa}$ & 0.45 & $75 \mathrm{MPa}$ & $1 \mathrm{MPa}$ \\
\hline
\end{tabular}

Using these material parameters results in a good agreement of experiment and simulation (see Figure 8) up to a displacement of $1.4 \mathrm{~mm}$, according to a plastic strain value of $13 \%$.

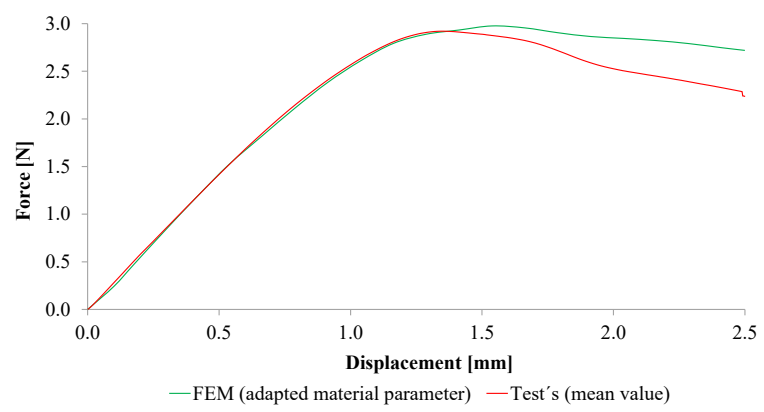

Figure 8: Comparison of experiment and FEA: illustration of the adequate precision of constitutive law to describe plastic deformation. 
In experimental crush resistance analysis an approximate mean force of $(164.04 \pm 9.71) \mathrm{mN}$ was measured after microstent ovalization to $1.1 \mathrm{~mm}(n=7)$. As a result of plastic deformation, a permanent deformation of $4.5 \%$ was measured after the test compared to the initial diameter.

The load case crush resistance was successfully implemented in the FEA model. In the simulation, the maximum force at a plate distance of $1.1 \mathrm{~mm}$ was $139.43 \mathrm{mN}$. The reopening diameter corresponds to the initial diameter of $2.28 \mathrm{~mm}$. Figure 9 shows the stress profile at a plate distance of $1.1 \mathrm{~mm}$. No plastic deformations appear. The highest stresses of approximately $72.59 \mathrm{MPa}$ occur at the nodes of the radii.

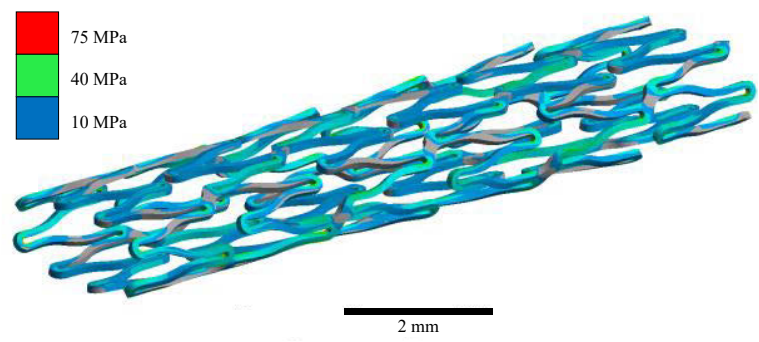

Figure 9: Visualization of the stresses occurring during the simulation of the load case crush resistance at a plate distance of $1.1 \mathrm{~mm}$.

\section{Discussion}

The experimental mean value curve and the simulation curve of the 3-point bending test correspond well for elastic strains and plastic strains up to $13 \%$. Therefore, the material model is assumed as sufficiently accurate since higher plastic strain values would be an exclusion criterion for a specific microstent design, anyway.

There is a good agreement between simulation and experimental test for crush resistance, see Figure 10. The maximum force of $139.43 \mathrm{mN}$ obtained in the simulation corresponds to $85 \%$ of the measured maximum force. This deviation is related to manufacturing process related variations geometrical variation of semi-finished products and microstent dimensions, e.g. diameter, wall thickness or strut widths. The FEA-model represents the mean value of material and geometry.

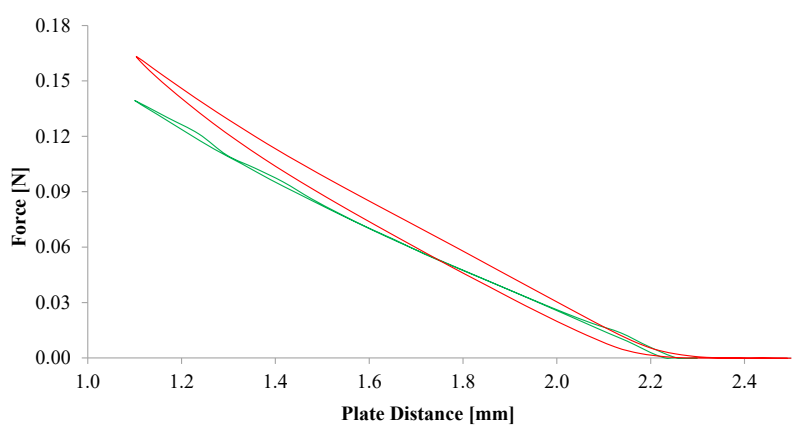

— FEM "Crush-Resistance" (mod. Model \& Material) — Test "Crush-Resistance" (averaged)

Figure 10: Comparison of the loading and unloading curve of the simulation and the mean curve of the experimental investigation.

Finally, it can be stated that the FEA model is sufficiently accurate for optimizing the stent design in terms of mechanical performance. It substantiates the importance of a realistic material model and illustrates the significance of numerical simulations. The implementation of further load cases, such as the investigation of the bending stiffness and the determination of the radial force are planned.

\section{Author Statement}

Research funding: Financial support by the Federal Ministry of Education and Research (BMBF) within RESPONSE "Partnership for Innovation in Implant Technology" is gratefully acknowledged. Conflict of interest: Authors state no conflict of interest.

\section{References}

[1] Diagnostic and therapy before assisted reproductive treatments. Guideline of the DGGG, OEGGG and SGGG (S2KLevel, AWMF Registry No. 015/085, 02/2019). www.awmf.org, accessed june 30, 2021

[2] Wehmeyer, E. Kostenübernahme bei künstlicher Befruchtung. Gynäkologe 45, 2012; 487-491. https://doi.org/10.1007/s00129-012-2983-z

[3] Allahbadia GN, Merchant R. Fallopian Tube Recanalization: Lessons Learnt and Future Challenges. Women's Health 2010; vol. 6; issue: 4; 531- 549 .

[4] Dierke A. Development of a biodegradable microstent for minimally invasive treatment of Fallopian tube occlusions. Current Directions in Biomedical Engineering, vol. 6, no. 3, 2020, 74-77. https://doi.org/10.1515/cdbme-2020-3019

[5] Martin DP, Williams SF. Medical applications of poly-4hydroxybutyrate: a strong flexible absorbable biomaterial. Biochemical Engineering Journal. 2003;16(2)97-105. 